\title{
Duration of over- and under-treatment of hypothyroidism is associated with increased cardiovascular risk
}

\author{
Mads Lillevang-Johansen ${ }^{1,2}$, Bo Abrahamsen ${ }^{2,3,4,5}$, Henrik Løvendahl Jørgensen ${ }^{6,7}$, Thomas Heiberg Brix ${ }^{1}$ and \\ Laszlo Hegedüs ${ }^{1}$
}

${ }^{1}$ Department of Endocrinology and Metabolism, Odense University Hospital, Odense, Denmark, ${ }^{2}$ Institute of Clinical Research, University of Southern Denmark, Odense, Denmark, ${ }^{3}$ Odense Patient data Explorative Network OPEN, University of Southern Denmark, Odense, Denmark, ${ }^{4}$ Department of Medicine, Holbæk Hospital, Holbæk, Denmark, ${ }^{5}$ Nuffield Department of Orthopaedics, Rheumatology and Musculoskeletal Sciences, University of Oxford, Oxford, UK, ${ }^{6}$ Department of Clinical Biochemistry, Hvidovre Hospital, Copenhagen, Denmark, and ${ }^{7}$ Department of Clinical Medicine, University of Copenhagen, Copenhagen, Denmark

\section{Correspondence} should be addressed to M Lillevang-Johansen Email

mlillevang@health.sdu.dk

\begin{abstract}
Objective: To investigate the association between hypothyroidism and cardiovascular disease (CVD) in both treated and untreated hypothyroid patients, and the consequences of over-and under-treatment with respect to cardiovascular risk.

Design: A registry-based case-control study nested within a population-based cohort of 275467 individuals with at least one serum thyroid stimulating hormone (TSH) measurement in the period of 1995-2011.

Methods: Incident cases of CVD were matched with controls according to gender, age and year of birth. Conditional logistic regression analyses were performed to calculate CVD risks associated with exposure to hypothyroidism, with adjustment for 19 pre-existing comorbidities, including cardiovascular disease and diabetes, using the Charlson Comorbidity Index.

Results: Overall, 20487 individuals experienced CVD (9.4\%, incidence rate 13.1 per 1000 person-years, 95\% confidence interval (CI), 13.0-13.3). Risk of CVD was increased in untreated hypothyroidism compared to euthyroidism (odds ratio (OR): 1.83 (95\% Cl: 1.43-2.35; $P<0.001)$ ). Cardiovascular risk was increased in both treated and untreated hypothyroid individuals per half year of elevated TSH (OR: 1.11 (95\% Cl: 1.06-1.16; $P<0.001$ ) and OR: 1.15 (95\% Cl: 1.09-1.23; $P=0.001)$, respectively). In patients treated with levothyroxine, OR for CVD was $1.12(95 \% \mathrm{Cl}: 1.06-1.18 ; P<0.001)$ for each 6 months of decreased TSH.

Conclusion: Cardiovascular risk is increased in untreated, but not in treated hypothyroid patients. Among those with treated hypothyroidism, duration of decreased TSH (overtreatment) had a similar impact on cardiovascular risk as duration of elevated TSH (under-treatment), highlighting the importance of initiating treatment and maintaining biochemical euthyroidism in hypothyroid patients in order to reduce the risk of CVD and death.
\end{abstract}

\section{Introduction}

Hypothyroidism, a very prevalent endocrine disease with a lifetime risk of $2-3 \%(1)$, has been linked to impaired quality of life (2), loss of labor market income and increased risk of disability pension (3), as well as a number of somatic morbidities such as diabetes and pulmonary disease (4). A target of thyroxine (T4) and triiodothyronine (T3), the cardiovascular system is affected by hypothyroidism due to changes in 
cardiovascular dynamics, contractility and accelerated atherosclerosis $(5,6)$. Although questioned until recently (7), excess mortality in hypothyroidism seems to be in the range of $38-46 \%(8,9)$, with cardiovascular mortality being the most important cause of death. Disagreement persists as to whether hypothyroidism is independently associated with increased cardiovascular risk. While some studies find increased cardiovascular risk $(4,10$, $11)$, others do not $(12,13,14)$. These differences may be due to heterogeneity in study populations, lack of or differences in confounder control, power, definition of cardiovascular disease (CVD), and, above all, failure to consider changing thyroid status. Furthermore, although psychiatric disease is associated with both cardiovascular disease $(15,16)$ and hypothyroidism $(17)$, no previous study has taken this evident confounder into consideration. Most importantly, previous studies have not investigated the effect of treatment of hypothyroidism on cardiovascular risk or the possible consequence of overtreatment. While randomized clinical trials (RCTs) found that thyroid hormone replacement therapy in subclinical hypothyroidism improved cardiovascular risk factors such as cholesterol and endothelial function (18) and diastolic dysfunction (19), the studies were not able assess whether this leads to a decreased risk of CVD. Moreover, few studies have investigated the possible hazards duration of over- and under-treatment. In a study of 17684 levothyroxine (LT4)-treated hypothyroid patients, Flynn et al. found that while there was an increased risk of CVD in treated patients with high thyroid-stimulating hormone (TSH) levels, this was also the case in patients with suppressed TSH (20). Given that $30-50 \%$ of hypothyroid patients treated with LT4 become hyperthyroid during treatment $(21,22)$, and recognizing that hyperthyroidism is associated with increased mortality $(23,24)$, major osteoporotic fractures $(25)$ and CVD (26), it remains pertinent to investigate a possible association between overtreatment of hypothyroidism and subsequent cardiovascular risk.

Utilizing a large cohort of biochemically documented hypothyroid individuals, we aimed at investigating cardiovascular risk in treated and untreated hypothyroid individuals compared to euthyroid individuals. Employing Danish Medical Registers, we controlled for both somatic and psychiatric comorbidity. Furthermore, we investigated the effect of duration of thyroid dysfunction, as a measure of over- and under-treatment, on cardiovascular risk.

\section{Subjects and methods}

\section{Study design}

This is a case-control study nested within a populationbased cohort, to ascertain cardiovascular risk in biochemically verified hypothyroid individuals.

\section{Study population}

The cohort was composed of 275467 individuals on the island of Funen, Denmark, who, in the period January 1, 1995, to January 1, 2011, had their TSH measured at least once. TSH measurements may be performed on indication, and as part of a general test. The test results were registered in the Odense Patient data Explorative Network (OPEN) and have been utilized previously (9, 24). Using a unique personal identifier, the data were crosslinked to the Danish National Patient Registry, which contains diagnoses from hospital admissions based on the International Classification of Diseases (ICD)-8 and ICD-10 (January 1, 1977), as well as outpatient visits (January 1, 1995) (27), the Danish National Prescription Registry (DNPrR) containing data on all medical prescriptions since January 1, 1995 (28), and the Danish Register of Causes of Death (29), which contains mortality data. In order to only investigate incident cases of hypothyroidism, we used a wash-out period of 1 year, hence excluding individuals with a TSH determination before 1996. After excluding individuals with known use of thyroid medication, thyroid surgery or radioactive iodine treatment prior to the first TSH determination, as well as individuals with hyperthyroidism, pre-existing pituitary disease, known CVD, age below 18 years, and those who emigrated or were lost to follow-up, 218701 individuals were initially included in the cohort (Fig. 1). Follow-up of the participants lasted from the date of the first thyroid function test to development of CVD, death or end of study (November 30, 2012).

A case-control study was nested within the cohort. Incident CVD cases were matched with up to three controls according to age at CVD, year of birth ( \pm 1 year) and gender through incidence density sampling.

\section{Outcomes}

Incident CVD events, as registered in the DNPR: CVD was defined as a composite of myocardial infarction (MI; 


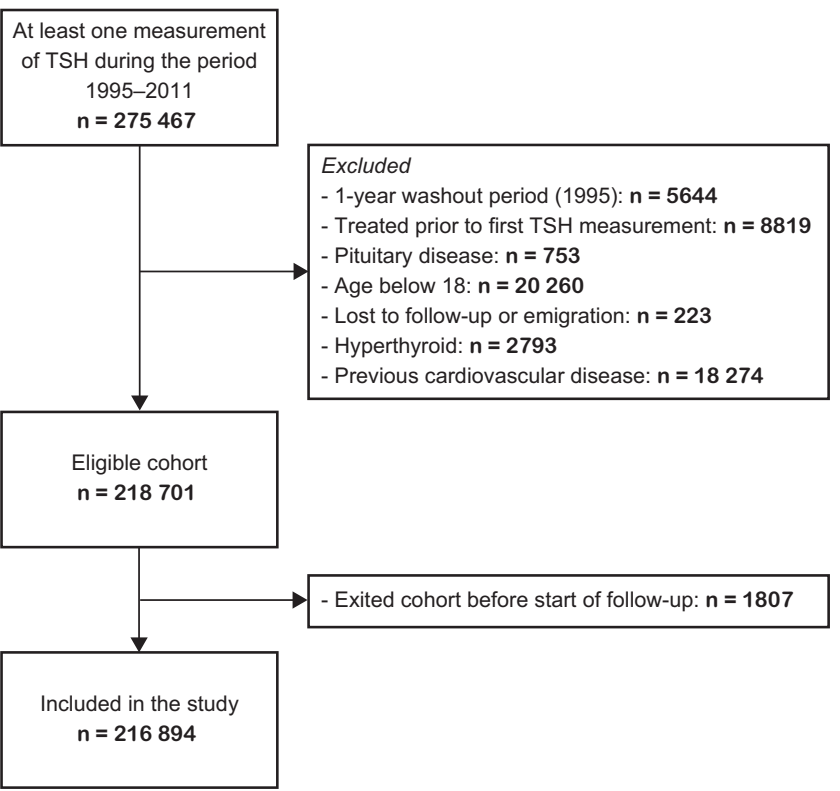

Figure 1

Flowchart describing the inclusion of individuals in the study.

defined by the ICD- 8 code 410 and by ICD-10 codes I21I22), stroke (ICD-8 codes 430-434, as well as ICD-10 codes I60-I64), atrial fibrillation (AF; ICD-8 code 427 and the ICD-10 code I48), heart failure (HF; ICD- 8 code 428 and the ICD-10 code I50) and cardiovascular death defined by ICD-8 codes 390-458 and ICD-10 codes I00-I99, as registered in the Danish Register of Causes of Death. The composite was defined by the first registered event of the above, regardless of diagnosis. When considering single outcomes (e.g. AF or HF), in the case of multiple events with the same diagnosis per individual, the first registered event of the type was used.

\section{Exposure}

Exposure was treated or untreated hypothyroidism, defined as having at least two measurements of elevated TSH within a period of 6 months, separated by at least 14 days.

Treatment was defined as having filled at least one prescription of LT4 during follow-up or having filled at least two prescriptions of LT4 within the first year following an elevated initial $\mathrm{TSH}$, as registered in the DNPrR.

Euthyroidism was defined as serum TSH between 0.3 and $4.0 \mathrm{mIU} / \mathrm{L}$. All TSH determinations were performed in the same laboratory. Methods of measurement have been described in detail elsewhere $(9,24,30,31)$.
Considering the 14-day minimum between measurements of TSH, the data was left-truncated by 14 days. Patients who in this period developed CVD, died or reached end of the cohort were excluded $(n=1807)$, leaving 216894 individuals eligible for study (Fig. 1). Due to repeat testing, and the fact that exposure was defined by the initial TSH measurement, euthyroid individuals could become hyper- and hypothyroid during follow-up. Thus, 2992 euthyroid individuals became hyperthyroid, while 3291 became hypothyroid. In the main analysis, euthyroid subjects were censored at the time of development of thyroid disease, with sensitivity analyses performed as described below.

\section{Confounders}

The Charlson Comorbidity Index (CCI) (32) was calculated for each individual at cohort entry using the DNPR, excluding CVD diagnoses. Hyperlipidemia, hypertension, diabetes and psychiatric morbidity were determined using the DNPR and DNPrR (Supplementary Table 1, see section on supplementary data given at the end of this article). In the nested case-control study, CCI and comorbidities were calculated at the time of CVD for cases, and the corresponding time for matched controls.

\section{Statistical analysis}

Statistical analyses were performed using Stata V14.1 (Stata Corporation, Inc.) and SAS version 9.4 (SAS Institute Inc.) through virtual private network access to Statistics Denmark.

CVD cases were matched 1:3 by age, gender and year of birth ( \pm 1 year), using the sttocc command in Stata. The sttocc command uses incidence density sampling, calculating age at the time of CVD for the cardiovascular cases and matching them with controls who at the same age as the case have not experienced a cardiovascular event. Thus, a cardiovascular case may serve as a control at a certain age where the case has not yet experienced CVD.

Adhering to case-control principles (33), characteristics of the nested case-control analyses were described at the time of cardiovascular event, while baseline characteristics of the cohort were those present at entry into the cohort. Baseline characteristics were analyzed using chi-squared test, Mann-Whitney $U$ test and $t$-test, as deemed appropriate.

Case-control analyses were performed using conditional logistic regression with results shown as 
unadjusted and adjusted odds ratios (OR) with 95\% confidence intervals (CIs) and adjusting for CCI, hyperlipidemia, hypertension, diabetes and psychiatric morbidities in steps within the statistical models. We prespecified stratified analyses for age above and below 65 years of age at the first TSH measurement, gender and single outcomes.

As thyroid status may vary over time, a dynamic model using 6-month periods of elevated TSH, or decreased TSH in the treated population, was applied in the regression analysis in order to analyse thyroid status as a dichotomous time-varying covariate. This made it possible to analyze the association between over- and under-treatment of hypothyroidism and cardiovascular risk. We collated TSH data using a conservative assumption, according to which periods where no TSH measurement had been performed were considered periods of euthyroidism. This means that a person may actually be hypothyroid, but be regarded as euthyroid because of lack of TSH determination within a 6-month period.

In order to take into account that a survival bias may be introduced in the treated patients due to the possibility of treatment being initiated at any time after the first TSH measurement, post hoc sensitivity analyses were performed by starting follow-up of the cohort 1 year after the first measurement of TSH, excluding anyone who experienced CVD, died or reached the end of study during this period. Any individual starting treatment after this point in time was regarded as untreated. Matching of CVD remaining cases was performed again, as was the regression analysis.
Finally, sensitivity analysis was performed where individuals were not censored due to the development of thyroid dysfunction during the course of follow-up.

All tests were two-tailed, and significant differences between the groups were defined by $P$ values below 0.05 .

\section{Ethics}

There was no patient involvement in the design or analysis of this study. The data used in the study are anonymized, and the identity of the participants remain unknown to the investigators. The project is approved by the Danish Data Protection Agency. OPEN is an approved research institution permitted to access data hosted by Statistics Denmark (Project 704047).

\section{Results}

\section{Description of cohort}

216894 individuals from the cohort were followed for CVD over a median time of 7.0 years (interquartile range (IQR): 4.1-10.4 years), constituting 1559553 person-years. 20487 individuals experienced CVD (9.4\%, incidence rate: 13.1 per 1000 person-years, 95\% CI: 13.0-13.3). At time of first TSH measurement, the corresponding serum concentrations of T4 were significantly lower in subsequently treated hypothyroid individuals than in those remaining untreated (Table 1).

Table 1 Baseline characteristics of the cohort.

\begin{tabular}{l} 
Mean age (s.D.) \\
Sex \\
Females \\
Males \\
CCI $^{\S}$ \\
0 \\
1 \\
2 \\
$\geq 3$ \\
Hyperlipidemia \\
Hypertension \\
Diabetes \\
Psychiatric morbidity \\
Median follow-up, years (IQR) \\
Median TSH, mIU/L (IQR) \\
Median T4, nmol/L (IQR) \\
Median T3, nmol/L (IQR) \\
\hline
\end{tabular}

\begin{tabular}{|c|c|}
\hline $\begin{array}{l}\text { Euthyroid } \\
(n=214214)\end{array}$ & $\begin{array}{l}\text { Hypothyroid treated } \\
\qquad(n=2058)\end{array}$ \\
\hline $49.6(17.8)$ & $54.3(17.3)$ \\
\hline 122549 (57.2\%) & $1730(84.1 \%)$ \\
\hline 91655 (42.8\%) & $328(15.9 \%)$ \\
\hline $182226(85.1 \%)$ & $1751(85.1 \%)$ \\
\hline $23703(11.1 \%)$ & $234(11.4 \%)$ \\
\hline $4720(2.2 \%)$ & $42(2.0 \%)$ \\
\hline $3565(1.7 \%)$ & $31(1.5 \%)$ \\
\hline $8666(4.0 \%)$ & $92(4.5 \%)$ \\
\hline $65098(30.4 \%)$ & $779(37.9 \%)$ \\
\hline $8919(4.2 \%)$ & $109(5.3 \%)$ \\
\hline 63988 (29.9\%) & 670 (32.6\%) \\
\hline $7.0(4.1-10.4)$ & $8.2(4.9-11.5)$ \\
\hline $1.3(0.9-1.9)$ & $9.2(6.1-20.2)$ \\
\hline 115 (99-133) & 91 (71-109) \\
\hline $1.95(1.7-2.3)$ & $1.64(1.3-1.9)$ \\
\hline
\end{tabular}

\begin{tabular}{c} 
Hypothyroid \\
untreated $(n=622)$ \\
\hline $55.4(19.4)$ \\
$440(70.7 \%)$ \\
$182(29.3 \%)$ \\
$510(82.0 \%)$ \\
$73(11.7 \%)$ \\
$21(3.4 \%)$ \\
$18(2.9 \%)$ \\
$42(6.8 \%)$ \\
$243(39.1 \%)$ \\
$40(6.4 \%)$ \\
$170(27.3 \%)$ \\
$5.3(3.3-8.3)$ \\
$5.5(4.7-6.7)$ \\
$109(95-126)$ \\
$1.80(1.6-2.1)$ \\
\end{tabular}

\begin{tabular}{|c|c|c|}
\hline \multicolumn{3}{|c|}{$P$ values } \\
\hline *ET & ${ }^{\dagger} \mathrm{EU}$ & 抽 \\
\hline 0 & $<0.0001$ & 0.2 \\
\hline 0 & $<0.0001$ & $<0.0001$ \\
\hline 0.9 & 0.02 & 0.03 \\
\hline
\end{tabular}

Apart from follow-up time, measures are reported at time of the initial TSH measurement. Percentage decimals in excess due to rounding

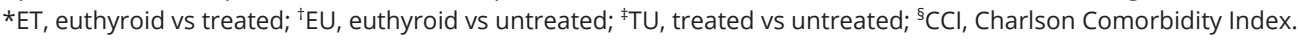




\section{Nested case-control study}

The 20487 CVD cases were matched to 60621 controls by age, gender and year of birth ( \pm 1 year). Briefly, CVD cases, as opposed to non-CVD controls, had significantly more pre-existing comorbidity with regard to CCI, hyperlipidemia, hypertension, diabetes and psychiatric diseases (Table 2). 145 of the CVD cases (0.7\%) could not be matched to any controls and were excluded from the subsequent analyses.

Conditional logistic regression (Table 3) showed an increased risk of developing CVD in untreated hypothyroid individuals (OR: 1.83 , 95\% CI: 1.43-2.35; $P<0.001$ ), while it was not increased in the treated hypothyroid individuals (OR: 0.83, 95\% CI: 0.71-0.96; $P=0.02$ ). As evident from Table 3, adding additional covariates to the model (e.g. adjusting for CCI, hyperlipidemia, hypertension, diabetes and psychiatric morbidity) in different combinations did not significantly alter the risk estimates.

Moreover, there was a dose-response relationship between out-of-target TSH and CVD. Hence, for every 6 months of elevated TSH, the OR for CVD was 1.11 (95\% CI: $1.06-1.16 ; P<0.001)$ in the treated hypothyroid individuals, and 1.15 (95\% CI: $1.09-1.23 ; P<0.001$ ) in the untreated. This corresponds to a $184 \%$ and $305 \%$ increased cardiovascular risk per 5 years of hypothyroidism in treated and untreated hypothyroid individuals, respectively. Periods of decreased TSH in the treated hypothyroid individuals, a proxy for overtreatment, showed significantly increased risk of CVD per 6 months of decreased TSH was significantly increased (OR: 1.12, 95\% CI: $1.06-1.18 ; P<0.001)$, corresponding to a $211 \%$ increased cardiovascular risk per 5 years of decreased TSH in treated hypothyroid individuals.
Analyses stratifying for gender, age below and above 65 years, as well as the individual outcomes of the composite score were performed (Table 4). Cardiovascular risk was significantly increased in untreated hypothyroid males and females, but not in the treated individuals. Untreated subjects $\geq 65$ years were at increased risk of CVD, which was not the case in the treated. Cardiovascular risk was also increased, albeit not statistically significant, in untreated hypothyroid individuals $<65$ years. This may be due to the low number of exposed individuals who experienced an outcome in this group $(n=34)$. For the individual cardiovascular outcomes, cardiovascular risk in treated hypothyroid individuals was not significantly increased compared to euthyroid individuals. In contrast, risk of $\mathrm{HF}$ and $\mathrm{AF}$ was increased in untreated individuals (Table 4).

\section{Sensitivity analyses}

Since the treated individuals could start treatment at any point during follow-up, there is a risk of introducing a survival bias in this group. The mean time from the first TSH measurement until treatment start was 0.9 years (s.D. 1.8 ) in the treated individuals. Therefore, in a sensitivity analysis, we further excluded all individuals from the cohort who experienced a cardiovascular event, end of study or died before this point in time, and matched the remaining cardiovascular cases to controls. When performing conditional logistic regression, in this setting, the results were essentially the same in the untreated individuals, while cardiovascular risk in the treated individuals was similar to that of the euthyroid individuals (data not shown).

Table 2 Characteristics and comorbidities of cardiovascular cases and their respective controls at the time of event in the nested case-control analysis.

\begin{tabular}{l}
\hline \\
\hline Mean age (s.D.) \\
Females \\
$\mathrm{CCl}$ \\
0 \\
1 \\
2 \\
$\geq 3$ \\
Hyperlipidemia \\
Hypertension \\
Diabetes \\
Psychiatric comorbidity \\
\hline
\end{tabular}

\begin{tabular}{c}
\hline CVD cases $(n=20487)$ \\
\hline $66.8(14.7)$ \\
$10305(50.3 \%)$ \\
$11906(58.1 \%)$ \\
$4949(24.2 \%)$ \\
$1672(8.2 \%)$ \\
$1960(9.6 \%)$ \\
$4814(23.5 \%)$ \\
$16795(82.0 \%)$ \\
$2854(13.9 \%)$ \\
$10770(52.6 \%)$ \\
\hline
\end{tabular}

\begin{tabular}{ccc}
\hline Controls $(n=60621)$ & & P values \\
\hline $66.8(14.7)$ & & - \\
$30474(50.3 \%)$ & & - \\
& & \\
$43542(71.8 \%)$ & & \\
$11701(19.3 \%)$ & & \\
$2966(4.9 \%)$ & & \\
$2412(4.0 \%)$ & & $<001$ \\
$10710(17.7 \%)$ & $<001$ \\
$40257(66.4 \%)$ & $<0.0001$ \\
$5944(9.8 \%)$ & $<0.0001$ \\
$27208(44.9 \%)$ & & $<$ \\
\hline
\end{tabular}

Differences tested by chi-squared test and Mann-Whitney $U$ test. Percentage decimal in excess due to rounding. $P$ values for comparison of matched parameters left out.

$\mathrm{CCl}$, Charlson Comorbidity Index. 
Table 3 Nested case-control analysis using conditional logistic regression of exposure to treated and untreated biochemical hypothyroidism as predictor of cardiovascular risk.

\begin{tabular}{|c|c|c|c|c|}
\hline \multirow[b]{2}{*}{ Statistical model } & \multicolumn{2}{|c|}{ Treated hypothyroidism $(n=636)$} & \multicolumn{2}{|c|}{ Untreated hypothyroidism $(n=188)$} \\
\hline & OR $(95 \% \mathrm{Cl})$ & $P$-Value & OR $(95 \% \mathrm{Cl})$ & $P$-Value \\
\hline $\mathrm{OR}_{\mathrm{CVD}}$ & $0.83(0.71-0.96)$ & 0.02 & $1.83(1.43-2.35)$ & $<0.001$ \\
\hline $\mathrm{OR}_{\mathrm{CVD}}: \mathrm{CCl}$ & $0.82(0.70-0.96)$ & 0.01 & $1.75(1.35-2.26)$ & $<0.001$ \\
\hline $\mathrm{OR}_{\mathrm{CVD}}: \mathrm{HL}+\mathrm{HT}+\mathrm{DM}$ & $0.83(0.71-0.97)$ & 0.02 & $1.79(1.39-2.32)$ & $<0.001$ \\
\hline $\mathrm{OR}_{\mathrm{CVD}}$ : psychiatric comorbidity & $0.82(0.71-0.96)$ & 0.01 & $1.88(1.46-2.42)$ & $<0.001$ \\
\hline $\mathrm{OR}_{\mathrm{CVD}}: \mathrm{CCl}+\mathrm{HL}+\mathrm{HT}+\mathrm{DM}$ & $0.83(0.71-0.98)$ & 0.02 & $1.74(1.34-2.26)$ & $<0.001$ \\
\hline $\mathrm{OR}_{\mathrm{CVD}}: \mathrm{CCl}+$ psychiatric morbidity & $0.82(0.70-0.96)$ & 0.01 & $1.79(1.38-2.31)$ & $<0.001$ \\
\hline $\mathrm{OR}_{\mathrm{CVD}}:$ All & $0.83(0.71-0.98)$ & 0.02 & $1.76(1.36-2.29)$ & $<0.001$ \\
\hline $\mathrm{OR}_{\mathrm{CVD}}$ : per 6 months of elevated TSH & $1.11(1.06-1.16)$ & $<0.001$ & $1.15(1.09-1.23)$ & $<0.001$ \\
\hline $\mathrm{OR}_{\mathrm{CVD}}$ : per 6 months of decreased TSH & $1.12(1.06-1.18)$ & $<0.001$ & - & \\
\hline
\end{tabular}

Adjusted for Charlson Comorbidity Index, hyperlipidemia, hypertension, diabetes and psychiatric comorbidities at point of cardiovascular event, in order to adhere to case-control principles.

$\mathrm{CCl}$, Charlson Comorbidity Index; DM, diabetes mellitus; HL, hyperlipidemia; HT, hypertension.

When considering the euthyroid individuals who developed hypothyroidism during the cohort as hypothyroid from the date of development of hypothyroidism and forward, untreated hypothyroid individuals still had an increased cardiovascular risk compared to euthyroid individuals (OR: 1.50 (95\% CI: $1.29-1.73 ; P<0.001)$ ), while there was no increased risk in treated hypothyroid individuals (OR: 0.84 (95\% CI: $0.75-0.95 ; P=0.004)$ ).

\section{Discussion}

In this large-scale, long-term follow-up study of individuals with biochemically verified hypothyroidism and full prescription information, we demonstrate that untreated hypothyroid individuals are at increased risk of CVD compared to euthyroid individuals. Unique to this study, which explored the effect of duration of thyroid dysfunction, we found that cardiovascular risk is further increased as a function of the cumulative duration of elevated TSH in both treated and untreated hypothyroid individuals. Of pivotal importance, taking into account periods of decreased TSH in treated individuals, as a measure of overtreatment, the risk of CVD per 6 months of decreased TSH was also increased. The results indicate that both over- and under-treatment of hypothyroidism are associated with increased cardiovascular risk.

While several previous studies have investigated a possible association between hypothyroidism and CVD $(4,10,12,13,14,20,34,35,36,37,38,39,40)$, disagreement still persists. The conflicting conclusions may be attributed to differences with regard to study design, the definition of CVD, cardiovascular outcomes investigated, and not least definition of hypothyroidism. As an example, some studies only use one measurement

Table 4 Nested case-control analysis of exposure to treated and untreated biochemical hypothyroidism as predictor of cardiovascular risk.

\begin{tabular}{|c|c|c|c|c|c|c|}
\hline & \multicolumn{3}{|c|}{ Hypothyroidism treated } & \multicolumn{3}{|c|}{ Hypothyroidism untreated } \\
\hline & $n$ & OR $(95 \% \mathrm{Cl})$ & $P$ value & $n$ & OR $(95 \% \mathrm{Cl})$ & $P$ value \\
\hline \multicolumn{7}{|c|}{ Stratification by group } \\
\hline $\mathrm{OR}_{\mathrm{CVD}}$ : males & 44 & $0.81(0.58-1.15)$ & 0.24 & 36 & $1.93(1.25-2.98)$ & 0.003 \\
\hline $\mathrm{OR}_{\mathrm{CVD}}$ : females & 169 & $0.82(0.69-0.97)$ & 0.02 & 65 & $1.66(1.21-2.28)$ & 0.002 \\
\hline $\mathrm{OR}_{\mathrm{CVD}}: \geq 65$ & 149 & $0.85(0.71-1.03)$ & 0.10 & 67 & $1.93(1.40-2.66)$ & $<0.001$ \\
\hline $\mathrm{OR}_{\mathrm{CVD}}:<65$ & 65 & $0.72(0.53-0.96)$ & 0.03 & 34 & $1.31(0.83-2.07)$ & 0.25 \\
\hline \multicolumn{7}{|l|}{ Sub-outcomes } \\
\hline $\mathrm{OR}_{\mathrm{MI}}$ & 44 & $1.03(0.73-1.47)$ & 0.86 & 15 & $1.22(0.67-2.22)$ & 0.52 \\
\hline $\mathrm{OR}_{\mathrm{HF}}$ & 35 & $0.77(0.53-1.12)$ & 0.17 & 23 & $1.88(1.11-3.18)$ & 0.02 \\
\hline $\mathrm{OR}_{\mathrm{AF}}$ & 51 & $0.73(0.53-0.99)$ & 0.045 & 27 & $1.72(1.07-2.77)$ & 0.03 \\
\hline $\mathrm{OR}_{\text {stroke }}$ & 72 & $0.92(0.71-1.20)$ & 0.56 & 38 & $1.40(0.95-2.08)$ & 0.09 \\
\hline $\mathrm{OR}_{\mathrm{CV} \text { death }}$ & 72 & $0.74(0.57-0.96)$ & 0.02 & 27 & $1.31(0.83-2.06)$ & 0.25 \\
\hline
\end{tabular}

$\mathrm{AF}$, atrial fibrillation; $\mathrm{CV}$ death, cardiovascular death; $\mathrm{HF}$, heart failure; $n$, number of cardiovascular cases in each stratum; MI, myocardial infarction; OR, odds ratio. 
of TSH in the definition of hypothyroidism $(12,13,14$, $34,39,40)$. This approach allows for the possibility of misclassification, since normalization of an initially elevated TSH may occur in more than half of tested individuals who have their measurements repeated (41, 42). By utilizing repeat measurements in our operational definition of hypothyroidism, we strived to reduce the risk of attribution bias. Further, some studies are limited in their ability to control for comorbidities $(13,34,38)$. Since a higher burden of comorbidity is associated with worsening of cardiovascular mechanics (43), controlling only for a subset of these may hamper the interpretation of results. Notably, the control for psychiatric comorbidity is unique to our study, and pertinent in light of psychiatric morbidity being associated with both hypothyroidism and CVD $(15,16)$. On the other hand, controlling for hyperlipidemia, hypertension and psychiatric disease, conditions that may occur on the pathophysiological pathway between hypothyroidism and CVD, may introduce excessive correction not in line with casecontrol methods. In our study, we have used several different models to control for the impact of comorbidity. Though adjusting for these factors did not alter the risk estimates of our analysis significantly, this may not necessarily be true in other study populations.

We used a composite score of the most rigorously investigated CVDs with regard to hypothyroidism $(38,39$, $40,44)$. When subdividing according to these, we found a significantly increased risk of HF in untreated hypothyroid individuals. This is in concert with Rodondi et al. (12) who found an increased risk of congestive heart failure in hypothyroid patients. The fact that Selmer et al. (39) found that hypothyroidism was associated with a decreased risk of AF is weakened by the lack of definite subdivision into treated and untreated individuals. While risk estimates for MI, stroke and cardiovascular death were increased in untreated hypothyroid individuals, at the same level as in $\mathrm{HF}$ and AF, these were not statistically significant, possibly because of low power when subdividing the outcomes.

Although cardiovascular risk increases with age, some studies have not presented age-stratified analysis $(12,13,14,20,34)$. We found significantly increased risk of CVD in untreated hypothyroid individuals $\geq 65$ years. This increased cardiovascular risk could also be observed in individuals $<65$ years, albeit then statistically insignificant. The lack of statistical significance in the younger age group may be explained the low event rate in younger subjects, hence only 34 cardiovascular cases were present in the untreated group $<65$ years. While current guidelines for treatment of hypothyroidism advocate for treating elderly patients $(45,46)$, our results suggest that this recommendation can be extended to younger ages as well, as suggested in recent studies increased cardiovascular risk in younger age groups $(11,38)$.

Most studies did not have data to distinguish between treated and untreated individuals. Randomized clinical trials have found improvement of cardiovascular risk factors such as endothelial function, weight and cholesterol after treatment with $\operatorname{LT} 4(18,19)$, but none of these have been powered to investigate hard endpoints such as clinically overt CVD. The observational studies that have investigated the risk of CVD in treated hypothyroid individuals disagree on whether risk of CVD is increased or not $(11,20,44,47)$. Our study finds an increased cardiovascular risk in untreated but not in treated hypothyroid individuals, in line with Razvi et al. $(11,47)$. To our knowledge, ours is the first largescale cohort study investigating the association between duration of thyroid function (a measure of over- and under-treatment) and CVD. The risk demonstrated with decreased TSH in the present study is of significant clinical concern, considering that recent studies have reported a high prevalence of overtreatment in hypothyroid patients. Thus, in a sample of LT4-treated hypothyroid individuals, Somwaru et al. found that $41 \%$ of the patients had decreased TSH (21). In support of this, Mammen et al. found that approximately half of cases of incident thyrotoxicosis were in patients receiving LT4 (22). Because of the risk of overtreatment, and the inherent risk of CVD in relation to hyperthyroidism, the increased cardiovascular risk associated with duration of thyroid dysfunction may be the most important message of this study. As a physician, it is important to ensure that hypothyroid patients that receive thyroid hormone replacement therapy are monitored carefully, in order to avoid under- and over-treatment.

There are some limitations to this study. We did not have access to information regarding smoking status and alcohol use of the study participants, confounders that are linked to both hypothyroidism and CVD $(48,49)$. However, by using the CCI, which allows for adjustment of chronic obstructive lung disease as well as liver disease, which serve as proxies for smoking and alcohol consumption, we were partly able to adjust for these factors. We lack information on the reasons for initiating or withholding treatment, and we must consider the possibility of confounding by indication when interpreting the results in the treated and the untreated population. As such, a severely ill person may have a slightly elevated TSH, and experience an outcome in close 
relation to this measurement, thus falsely attributing the increased risk of CVD to that of hypothyroidism, and possibly not allowing this person to initiate treatment. However, the 14 days between measurements, combined with the results of the post hoc sensitivity analysis which sought to minimize this bias, suggest that this bias is of limited influence. Surprisingly, we found increased survival in the treated hypothyroid individuals. We cannot rule out the possibility of this finding being due to stricter medical attention to the treated hypothyroid individuals, which may have permitted early intervention for other conditions with a bearing on survival. Similarly, patients whose TSH levels were poorly controlled could potentially be suboptimally treated for other conditions such as hypertension or hyperlipidemia, which could inflate the apparent risk estimates. Further, a survival bias may have been introduced in the treated hypothyroid individuals, thus rendering them unable to be allocated in the treated group until they start treatment at some point during follow-up. Yet, our post hoc sensitivity analysis essentially confirmed the main analysis, indicating that findings were not appreciably influenced by this potential source of bias.

\section{Conclusion}

Cardiovascular risk was increased in untreated, but not in treated hypothyroid individuals, irrespective of age and gender. Importantly, a longer duration of decreased TSH, as a proxy for overtreatment, was associated with further increased risk of CVD, as was the duration of elevated TSH, an indicator of under-treatment. Though randomized clinical trials are need for definitive proof of causality, this study clearly demonstrates the need for meticulous monitoring of substitution therapy in hypothyroid individuals in order to avoid adverse cardiovascular events.

\section{Supplementary data}

This is linked to the online version of the paper at https://doi.org/10.1530/ EJE-19-0006.

\section{Declaration of interest}

$B$ A has institutional research contracts with UCB and Novartis outside the current study. M L-J, H L J, T H B and L H declare no conflicts of interest. All authors have completed the ICMJE uniform disclosure form at www.icmje. org/coi_disclosure.pdf.

\section{Funding}

M L-J is enrolled as a PhD student at the University of Southern Denmark, and is funded by the University of Southern Denmark, and Odense
University Hospital. M L-J has further received research grants from Inger Goldmanns Fond, The Danish Thyroid Patient Society, Odense University Hospital Research Fund, The Agnes \& Knut Mørk Foundation and Overlægerådets Forskningsfond.

\section{Author contribution statement}

All authors contributed to the design of the study, the interpretation of the results, and reviewed the manuscript. The authors had full access to all of the data in the study and take responsibility for the integrity of the data and the accuracy of the data analysis. Additional contributions: Dr Mads Nybo, Department of Clinical Biochemistry, Odense University Hospital, is acknowledged for his role in the initial data collection.

\section{References}

1 Carle A, Laurberg P, Pedersen IB, Knudsen N, Perrild H, Ovesen L, Rasmussen LB \& Jorgensen T. Epidemiology of subtypes of hypothyroidism in Denmark. European Journal of Endocrinology 2006 154 21-28. (https://doi.org/10.1530/eje.1.02068)

2 Winther KH, Cramon P, Watt T, Bjorner JB, Ekholm O, FeldtRasmussen U, Groenvold M, Rasmussen ÅK, Hegedus L \& Bonnema SJ. Disease-specific as well as generic quality of life is widely impacted in autoimmune hypothyroidism and improves during the first six months of levothyroxine therapy. PLOS ONE 2016 11 e0156925. (https://doi.org/10.1371/journal.pone.0156925)

3 Thvilum M, Brandt F, Brix TH \& Hegedus L. Hypothyroidism is a predictor of disability pension and loss of labor market income: a Danish register-based study. Journal of Clinical Endocrinology and Metabolism 201499 3129-3135. (https://doi.org/10.1210/jc.2014-1407)

4 Thvilum M, Brandt F, Almind D, Christensen K, Brix TH \& Hegedus L. Type and extent of somatic morbidity before and after the diagnosis of hypothyroidism. a nationwide register study. PLoS ONE 20138 e75789. (https://doi.org/10.1371/journal.pone.0075789)

5 Biondi B \& Klein I. Hypothyroidism as a risk factor for cardiovascular disease. Endocrine 200424 1-13. (https://doi.org/10.1385/ ENDO:24:1:001)

6 Razvi S, Jabbar A, Pingitore A, Danzi S, Biondi B, Klein I, Peeters R, Zaman A \& Iervasi G. Thyroid hormones and cardiovascular function and diseases. Journal of the American College of Cardiology 201871 1781-1796. (https://doi.org/10.1016/j.jacc.2018.02.045)

7 Thvilum M, Brandt F, Brix TH \& Hegedus L. A review of the evidence for and against increased mortality in hypothyroidism. Nature Reviews: Endocrinology 20128 417-424. (https://doi.org/10.1038/ nrendo.2012.29)

8 Thvilum M, Brandt F, Almind D, Christensen K, Hegedus L $\&$ Brix TH. Excess mortality in patients diagnosed with hypothyroidism: a nationwide cohort study of singletons and twins. Journal of Clinical Endocrinology and Metabolism 201398 1069-1075. (https://doi.org/10.1210/jc.2012-3375)

9 Lillevang-Johansen M, Abrahamsen B, Jorgensen HL, Brix TH $\&$ Hegedus L. Over- and under-treatment of hypothyroidism is associated with excess mortality: a register-based cohort study. Thyroid 201828 566-574. (https://doi.org/10.1089/thy.2017.0517)

10 Walsh JP, Bremner AP, Bulsara MK, O'Leary P, Leedman PJ, Feddema P $\&$ Michelangeli V. Subclinical thyroid dysfunction as a risk factor for cardiovascular disease. Archives of Internal Medicine 2005165 2467-2472. (https://doi.org/10.1001/archinte.165.21.2467)

11 Razvi S, Weaver JU, Vanderpump MP \& Pearce SH. The incidence of ischemic heart disease and mortality in people with subclinical hypothyroidism: reanalysis of the Whickham Survey cohort. Journal of Clinical Endocrinology and Metabolism 201095 1734-1740. (https:// doi.org/10.1210/jc.2009-1749)

12 Rodondi N, Newman AB, Vittinghoff E, de Rekeneire N, Satterfield S, Harris TB \& Bauer DC. Subclinical hypothyroidism and the risk of 
heart failure, other cardiovascular events, and death. Archives of Internal Medicine 2005165 2460-2466. (https://doi.org/10.1001/ archinte.165.21.2460)

13 Boekholdt SM, Titan SM, Wiersinga WM, Chatterjee K, Basart DC, Luben R, Wareham NJ \& Khaw KT. Initial thyroid status and cardiovascular risk factors: the EPIC-Norfolk prospective population study. Clinical Endocrinology 201072 404-410. (https://doi. org/10.1111/j.1365-2265.2009.03640.x)

14 Martin SS, Daya N, Lutsey PL, Matsushita K, Fretz A, McEvoy JW, Blumenthal RS, Coresh J, Greenland P, Kottgen A et al. Thyroid function, cardiovascular risk factors, and incident atherosclerotic cardiovascular disease: the atherosclerosis risk in communities (ARIC) study. Journal of Clinical Endocrinology and Metabolism $2017 \mathbf{1 0 2}$ 3306-3315. (https://doi.org/10.1210/jc.2017-00986)

15 Fiedorowicz JG. Depression and cardiovascular disease: an update on how course of illness may influence risk. Current Psychiatry Reports 201416 492. (https://doi.org/10.1007/s11920-014-0492-6)

16 Goldstein BI, Carnethon MR, Matthews KA, McIntyre RS, Miller GE, Raghuveer G, Stoney CM, Wasiak H, McCrindle BW, American Heart Association Atherosclerosis et al. Major depressive disorder and bipolar disorder predispose youth to accelerated atherosclerosis and early cardiovascular disease: a scientific statement from the American Heart Association. Circulation 2015132 965-986. (https://doi. org/10.1161/CIR.0000000000000229)

17 Thvilum M, Brandt F, Almind D, Christensen K, Brix TH \& Hegedus L. Increased psychiatric morbidity before and after the diagnosis of hypothyroidism: a nationwide register study. Thyroid 201424 802-808. (https://doi.org/10.1089/thy.2013.0555)

18 Razvi S, Ingoe L, Keeka G, Oates C, McMillan C \& Weaver JU. The beneficial effect of L-thyroxine on cardiovascular risk factors, endothelial function, and quality of life in subclinical hypothyroidism: randomized, crossover trial. Journal of Clinical Endocrinology and Metabolism 200792 1715-1723. (https://doi. org/10.1210/jc.2006-1869)

19 Monzani F, Di Bello V, Caraccio N, Bertini A, Giorgi D, Giusti C $\&$ Ferrannini E. Effect of levothyroxine on cardiac function and structure in subclinical hypothyroidism: a double blind, placebocontrolled study. Journal of Clinical Endocrinology and Metabolism 2001 86 1110-1115. (https://doi.org/10.1210/jcem.86.3.7291)

20 Flynn RW, Bonellie SR, Jung RT, MacDonald TM, Morris AD \& Leese GP. Serum thyroid-stimulating hormone concentration and morbidity from cardiovascular disease and fractures in patients on long-term thyroxine therapy. Journal of Clinical Endocrinology and Metabolism 201095 186-193. (https://doi.org/10.1210/jc.20091625)

21 Somwaru LL, Arnold AM, Joshi N, Fried LP \& Cappola AR. High frequency of and factors associated with thyroid hormone overreplacement and under-replacement in men and women aged 65 and over. Journal of Clinical Endocrinology and Metabolism 200994 1342-1345. (https://doi.org/10.1210/jc.2008-1696)

22 Mammen JS, McGready J, Oxman R, Chia CW, Ladenson PW \& Simonsick EM. Thyroid hormone therapy and risk of thyrotoxicosis in community-resident older adults: findings from the Baltimore longitudinal study of aging. Thyroid 201525 979-986. (https://doi. org/10.1089/thy.2015.0180)

23 Brandt F, Almind D, Christensen K, Green A, Brix TH \& Hegedus L. Excess mortality in hyperthyroidism: the influence of preexisting comorbidity and genetic confounding: a Danish nationwide register-based cohort study of twins and singletons. Journal of Clinical Endocrinology and Metabolism 201297 4123-4129. (https://doi. org/10.1210/jc.2012-2268)

24 Lillevang-Johansen M, Abrahamsen B, Jorgensen HL, Brix TH $\&$ Hegedus L. Excess mortality in treated and untreated hyperthyroidism is related to cumulative periods of low serum TSH.
Journal of Clinical Endocrinology and Metabolism 2017102 2301-2309. (https://doi.org/10.1210/jc.2017-00166)

25 Abrahamsen B, Jorgensen HL, Laulund AS, Nybo M, Brix TH \& Hegedus L. Low serum thyrotropin level and duration of suppression as a predictor of major osteoporotic fractures - the OPENTHYRO register cohort. Journal of Bone and Mineral Research 201429 2040-2050. (https://doi.org/10.1002/jbmr.2244)

26 Brandt F, Thvilum M, Almind D, Christensen K, Green A, Hegedus L \& Brix TH. Morbidity before and after the diagnosis of hyperthyroidism: a nationwide register-based study. PLOS ONE 2013 8 e66711. (https://doi.org/10.1371/journal.pone.0066711)

27 Schmidt M, Schmidt SA, Sandegaard JL, Ehrenstein V, Pedersen L, Sorensen HT. The Danish National Patient Registry: a review of content, data quality, and research potential. Clinical Epidemiology 20157 449-490. (https://doi.org/10.2147/CLEP.S91125)

28 Pottegard A, Schmidt SAJ, Wallach-Kildemoes H, Sorensen HT, Hallas J \& Schmidt M. Data resource profile: the Danish National Prescription Registry. International Journal of Epidemiology 201746 798-798f. (https://doi.org/10.1093/ije/dyw213)

29 Helweg-Larsen K. The Danish register of causes of death. Scandinavian Journal of Public Health 201139 26-29. (https://doi. org/10.1177/1403494811399958)

30 Abrahamsen B, Jorgensen HL, Laulund AS, Nybo M, Bauer DC, Brix TH \& Hegedus L. The excess risk of major osteoporotic fractures in hypothyroidism is driven by cumulative hyperthyroid as opposed to hypothyroid time: an observational register-based time-resolved cohort analysis. Journal of Bone and Mineral Research 201530 898-905. (https://doi.org/10.1002/jbmr.2416)

31 Jensen E, Hyltoft Petersen P, Blaabjerg O, Hansen PS, Brix TH, Kyvik KO \& Hegedus L. Establishment of a serum thyroid stimulating hormone (TSH) reference interval in healthy adults. The importance of environmental factors, including thyroid antibodies. Clinical Chemistry and Laboratory Medicine 200442 824-832. (https://doi. org/10.1515/CCLM.2004.136)

32 Charlson ME, Pompei P, Ales KL \& MacKenzie CR. A new method of classifying prognostic comorbidity in longitudinal studies: development and validation. Journal of Chronic Diseases 198740 373-383. (https://doi.org/10.1016/0021-9681(87)90171-8)

33 Vandenbroucke JP, von Elm E, Altman DG, Gotzsche PC, Mulrow CD, Pocock SJ, Poole C, Schlesselman JJ, Egger M \& STROBE Initiative. Strengthening the Reporting of Observational Studies in Epidemiology (STROBE): explanation and elaboration. Epidemiology 200718 805-835. (https://doi.org/10.1097/EDE.0b013e3181577511)

34 Imaizumi M, Akahoshi M, Ichimaru S, Nakashima E, Hida A, Soda M, Usa T, Ashizawa K, Yokoyama N, Maeda R et al. Risk for ischemic heart disease and all-cause mortality in subclinical hypothyroidism. Journal of Clinical Endocrinology and Metabolism 200489 3365-3370. (https://doi.org/10.1210/jc.2003-031089)

35 Rodondi N, den Elzen WP, Bauer DC, Cappola AR, Razvi S, Walsh JP, Asvold BO, Iervasi G, Imaizumi M, Collet TH et al. Subclinical hypothyroidism and the risk of coronary heart disease and mortality. JAMA 2010304 1365-1374. (https://doi.org/10.1001/ jama.2010.1361)

36 Karch A \& Thomas SL. Autoimmune thyroiditis as a risk factor for stroke: a historical cohort study. Neurology 201482 1643-1652. (https://doi.org/10.1212/WNL.0000000000000377)

37 Singh S, Duggal J, Molnar J, Maldonado F, Barsano CP \& Arora R. Impact of subclinical thyroid disorders on coronary heart disease, cardiovascular and all-cause mortality: a meta-analysis. International Journal of Cardiology 2008125 41-48. (https://doi.org/10.1016/j. ijcard.2007.02.027)

38 Chaker L, Baumgartner C, den Elzen WP, Ikram MA, Blum MR, Collet TH, Bakker SJ, Dehghan A, Drechsler C, Luben RN et al. Subclinical hypothyroidism and the risk of stroke events and fatal 
stroke: an individual participant data analysis. Journal of Clinical Endocrinology and Metabolism 2015100 2181-2191. (https://doi. org/10.1210/jc.2015-1438)

39 Selmer C, Olesen JB, Hansen ML, Lindhardsen J, Olsen AM, Madsen JC, Faber J, Hansen PR, Pedersen OD, Torp-Pedersen C et al. The spectrum of thyroid disease and risk of new onset atrial fibrillation: a large population cohort study. BMJ 2012345 e7895. (https://doi.org/10.1136/bmj.e7895)

40 Selmer C, Olesen JB, Hansen ML, von Kappelgaard LM, Madsen JC, Hansen PR, Pedersen OD, Faber J, Torp-Pedersen C \& Gislason GH. Subclinical and overt thyroid dysfunction and risk of all-cause mortality and cardiovascular events: a large population study. Journal of Clinical Endocrinology and Metabolism 201499 2372-2382. (https:// doi.org/10.1210/jc.2013-4184)

41 Meyerovitch J, Rotman-Pikielny P, Sherf M, Battat E, Levy Y \& Surks MI. Serum thyrotropin measurements in the community: fiveyear follow-up in a large network of primary care physicians. Archives of Internal Medicine 2007167 1533-1538. (https://doi.org/10.1001/ archinte.167.14.1533)

42 Somwaru LL, Rariy CM, Arnold AM \& Cappola AR. The natural history of subclinical hypothyroidism in the elderly: the cardiovascular health study. Journal of Clinical Endocrinology and Metabolism 201297 1962-1969. (https://doi.org/10.1210/jc.2011-3047)

43 Selvaraj S, Aguilar FG, Martinez EE, Beussink L, Kim KY, Peng J, Rasmussen-Torvik L, Sha J, Irvin MR, Gu CC et al. Association of comorbidity burden with abnormal cardiac mechanics: findings from the HyperGEN study. Journal of the American Heart Association 20143 e000631. (https://doi.org/10.1161/JAHA.113.000631)
44 Andersen MN, Olsen AM, Madsen JC, Faber J, Torp-Pedersen C, Gislason GH \& Selmer C. Levothyroxine substitution in patients with subclinical hypothyroidism and the risk of myocardial infarction and mortality. PLoS ONE 201510 e0129793. (https://doi.org/10.1371/ journal.pone.0129793)

45 Jonklaas J, Bianco AC, Bauer AJ, Burman KD, Cappola AR, Celi FS, Cooper DS, Kim BW, Peeters RP, Rosenthal MS et al. Guidelines for the treatment of hypothyroidism: prepared by the American Thyroid Association task force on thyroid hormone replacement. Thyroid 201424 1670-1751. (https://doi.org/10.1089/thy.2014.0028)

46 Pearce SH, Brabant G, Duntas LH, Monzani F, Peeters RP, Razvi S \& Wemeau JL. 2013 ETA guideline: management of subclinical hypothyroidism. European Thyroid Journal 20132 215-228. (https:// doi.org/10.1159/000356507)

47 Razvi S, Weaver JU, Butler TJ \& Pearce SH. Levothyroxine treatment of subclinical hypothyroidism, fatal and nonfatal cardiovascular events, and mortality. Archives of Internal Medicine 2012172 811-817. (https://doi.org/10.1001/archinternmed.2012.1159)

48 Brix TH, Hansen PS, Kyvik KO \& Hegedus L. Cigarette smoking and risk of clinically overt thyroid disease: a population-based twin case-control study. Archives of Internal Medicine 2000160 661-666. (https://doi.org/10.1001/archinte.160.5.661)

49 Hegedus L, Rasmussen N, Ravn V, Kastrup J, Krogsgaard K \& Aldershvile J. Independent effects of liver disease and chronic alcoholism on thyroid function and size: the possibility of a toxic effect of alcohol on the thyroid gland. Metabolism: Clinical and Experimental 198837 229-233. (https://doi.org/10.1016/00260495(88)90100-X)

Received 14 January 2019

Revised version received 4 April 2019

Accepted 26 April 2019 